Kinetic Reactions Modeling and Optimization of Claus Process

\title{
Kinetic Reactions Modeling and Optimization of Claus Process
}

$1^{\text {st }}$ Muhammad Arslan Zahid*

Dept. of Chemical and Materials Engineering

National University of Sciences and Technology

Islamabad, Pakistan

mzahid.pse1@scme.nust.edu.pk

$3^{\text {st }}$ Muhammad Mubashir***

Dept. of Chemical and Materials Engineering

National University of Sciences and Technology

Islamabad, Pakistan

mmubashir.pse1@ scme.nust.edu.pk

\author{
$2^{\text {nd }}$ Faisal Ali** \\ Dept of Chemical and Material Engineering \\ National University of Science and Technology \\ Islamabad Pakistan \\ fali.pse1@ scme.nust.edu.pk
}

\author{
$4^{\text {nd }}$ Faheem Iqbal**** \\ Dept of Chemical and Material Engineering \\ National University of Science and Technology \\ Islamabad Pakistan \\ mfaheem.msce19s@rcms.nust.edu.pk
}

\section{Abstract}

There are many pollution and environment problem in the human ecosystem. There are different methods are used to removal of sulfur from sour gases for example Basic Claus process and Modified Claus process . There are different chemical software are used for simulation and optimization of Claus process for example Aspen Plus and Chemcad ECT. The Gibbs free energy method is introduced and model of Claus process. There are new parameter are introduced in reaction furnace to reduce the error from $33 \%$ to $7 \%$. The waste heat boiler is installed at the reaction furnace in which high pressure stream is produced and study the decomposition the hydrogen sulphide. The new rate of reaction is introduced of the enhancement of $\mathrm{H}_{2}$ production in chemical process. The simulation of reaction furnace in Aspen plus software is the maximum utilization of process. Due to suitable operating condition of reaction furnace is caused the maximum destruction of ammonia gas in the reactor. When we are increasing the oxygen concentration and temperature of feed is causing decreasing the ammonia production in reaction furnace. It is below than acceptance value of ammonia is $150 \mathrm{ppm}$ in the reaction furnace. The presence of oxygen components, Sulfur oxide, hydroxide components are effect on decreasing the amount of ammonia in furnace and temperature is about at $1350^{\circ} \mathrm{C}$. It is noted that when the production of sulfur recovery is decrease in Claus process and the production of carbon monoxide is increase in the thermal section at the existence. Now we are work on parametric studies of furnace that could be causes the production of ammonia destruction and $\mathrm{CO}$ emission in the Claus process. Due to optimize the reaction furnace parameter are help to get large of 
Kinetic Reactions Modeling and Optimization of Claus Process

sulfur production, ammonia gas destruction, increased the catalyst life and decreased of dangerous gases.

Keywords: Sulfur Recovery Process, Enhancement of sulfur production, Reduction of ammonia gas.

\section{Introduction}

The sulfur recovery process is most important method for recovery of sulfur from sour gases. In the natural gases there are some bad containment are present in it. These gases are called sour gases. There are different process of recovery of sulfur like unsulfured, Low-CAT and modified Claus process [1]. The Modified Claus process is best method of sulfur recovery of Claus process. In modified Claus process the recovery of sulfur is $96 \%$. There are different reaction take place in Claus process. The modified Claus process is divided into two section first thermal combustion and second is catalytic section [2].

$$
\begin{aligned}
\mathrm{H}_{2} \mathrm{~S}+1.5 \mathrm{O}_{2} \longrightarrow \mathrm{SO}_{2}+\mathrm{H}_{2} \mathrm{O} \\
\mathrm{H}_{2} \mathrm{~S}+\mathrm{SO}_{2} \longrightarrow 1.5 \mathrm{~S}_{2}+2 \mathrm{H}_{2} \mathrm{O}
\end{aligned}
$$

The catalyst is used for Claus process is alumina and titanium oxide bed. In the reaction furnace the inlet feed temperature is $25^{\circ} \mathrm{C}$ and pressure is 1 atm. The ratio of $\mathrm{H}_{2} \mathrm{~S}: \mathrm{SO}_{2}$ is $2: 1$ reaction furnace is along with different quality of air to oxidize material [3]. The reaction furnace is operating at temperature of $975^{\circ} \mathrm{C}$ to $1200^{\circ} \mathrm{C}$ and residence time of reaction furnace is 0.5 to 2 second. The first section of reaction furnace is made up of refractory lined cylinder vessel and it is operated at low pressure at $22 \mathrm{~atm}$. The first is very important portion of the plant because in the first section sulfur is produced and other components are also produce like $\mathrm{SO}_{2}$ gas and these gases are caused big effect on the conversion. After the reaction furnace the waste heat boiler is installed in it. It is caused decreased the temperature of furnace from $1000^{\circ} \mathrm{C}$ to $260^{\circ} \mathrm{C}$ and tubes are passed from the reaction furnace and it is produced medium pressure steam [4].

According to EPA agency Environmental protecting agency the sulfur is reduced in petroleum products and work on increase the sulfur recovery efficiency up to $99 \%$ [5]. To get maximum efficiency of Claus process is important by optimization and parametric study of Claus process and work on improving the existing technology. To work on the reaction furnace and take an 
Kinetic Reactions Modeling and Optimization of Claus Process

optimum conditions to get a maximum sulfur recovery. Bennet and Meisen is worked on hydrogen sulphide gas and air system at temperature of 2000K. In his worked he is considered 36 chemical species and $\mathrm{N}_{2}$ gas are also included [6]. Monnery et is worked on Claus process by using Gibbs free energy method and calculation of Claus furnace reaction. Khudenko is worked on equilibrium reaction by increasing the oxygen concentration of Claus process by decreasing the equipment size [7]. Bassani et $\mathrm{Al}$ is worked on the gasification of coal instead of using the sulfur recovery unit process to enhance and increment of syngas and also decrease the recovery of sulfur and the emission of $\mathrm{CO}_{2}$ gas [8]. The performance of Claus process is $66 \%$ of the total recovery of sulfur. The furnace is installed in the Claus process for destruction of ammonia gas in the reaction furnace. There is some technical technique for the destruction of ammonia in the sulfur recovery unit. The first thing is the ammonia is struck at the pore of the bed of the reactor when the $\mathrm{SO}_{3}$ gas is reacted with $\mathrm{NH}_{3}$ gas to form ammonium salt. This ammonium salt is caused to deactivation of catalyst and also caused pressure drop of fluid flow [9]. Due to this causes it is cause increased in maintenance cost. There is formation of $\mathrm{SO}_{3}$ in the catalyst bed in the absence of NO. The $\mathrm{NO}$ is present in the catalyst bed it is act like an oxidation of $\mathrm{SO}_{2}$ to $\mathrm{SO}_{3}$ is called catalyst sulfonating. In the second the presence of ammonia gas in the sour gases can decreased in sulfur production [10]. When the ammonia gas is destruct in the reaction furnace are produce different products like nitrogen, hydrogen and water. In the Claus reaction the byproduct components is water when the concentration of water is increase then it effect on decrease the conversion of $\mathrm{H}_{2} \mathrm{~S}$ gas into elemental sulfur. The ammonia destruction is impact on size of equipment and there is some problem of formation of precipitation of ammonia salt in the sulfur recovery unit [11]. Clark et al has worked on effect of different gases like water and hydrogen sulphide gas on the ammonia pyrolysis at the operating temperature of furnace and at different residence time. Mohammad et al has worked on the oxygen enrichment because of increase in sulfur recovery production. These techniques are used to increase the production rate of sulfur and also increase in cost rate. It is also worked to use optimal kinetic model for effective production of sulfur [12]. 
Kinetic Reactions Modeling and Optimization of Claus Process

\section{Process Description of Claus Process}

\subsection{Method use for simulation}

There is different method use for simulation of Claus process. The most suitable and best method for simulation is Peng-Robison method. In the Peng-Robison method the hydrocarbon are used for simulation and it is used for vapor phase gas reaction and petroleum products.

$$
\mathrm{P}=\frac{R T}{V-b}-\frac{a(T)}{V(V+b)+b(V-b)}
$$

- $\mathrm{P}$ is pressure $(\mathrm{Pa})$

- $\mathrm{V}$ is molar volume $\left(\mathrm{m}^{3} \mathrm{~mol}^{-1}\right)$

- $\mathrm{R}$ is gas Constant $\left(8.314 \mathrm{~J} \mathrm{~mol}^{-1} \mathrm{k}^{-1}\right)$

- $\mathrm{T}$ is absolute Temperature $(\mathrm{K})$

- $\mathrm{P}_{\mathrm{C}}$ is critical pressure of component $(\mathrm{Pa})$

- $\quad \mathrm{Tc}$ is critical temperature for component $(\mathrm{K})$

\subsection{Process Description}

There are three streams in which feed is entering into the systems. In the first stream oxygen is entered into the stream at flowrate of $90 \mathrm{kmol} / \mathrm{hr}$ temperature of $32^{\circ} \mathrm{C}$ and pressure is 10 bars. Secondly second stream is entering into feed at temperature of $120^{\circ} \mathrm{C}$ and pressure is 2.4 bars.

The two streams are entering at one point and it mixed to each other in the splitter. The third stream is added into the process at different point at temperature of $50^{\circ} \mathrm{C}$ and flowrate is 388.1 $\mathrm{kmol} / \mathrm{hr}$. In the third stream the flowrate of $\mathrm{H}_{2} \mathrm{~S}$ gas is $159.1 \mathrm{kmol} / \mathrm{hr}$ and flowrate of water is $15.6 \mathrm{kmol} / \mathrm{hr}$ and flowrate of $\mathrm{CO}_{2}$ is $174.2 \mathrm{kmol} / \mathrm{hr}$. The reaction furnace is divided into section first Flame zone and second anoxic section. The Flame zone is operated at $1300^{\circ} \mathrm{C}$ and pressure of feed is 1.7 bars. The flame zone is caused exothermic reaction in which high amount of heat is released in this reactions [13].

These reactions are:

$$
\begin{gathered}
\mathrm{H}_{2} \mathrm{~S}+3 / 2 \mathrm{O}_{2} \longrightarrow \mathrm{SO}_{2}+\mathrm{H}_{2} \mathrm{O} \\
\mathrm{NH}_{3}+3 / 4 \mathrm{O}_{2} \longrightarrow 1 / 2 \mathrm{~N}_{2}+3 / 2 \mathrm{H}_{2} \mathrm{O}
\end{gathered}
$$


Kinetic Reactions Modeling and Optimization of Claus Process

These two reactions are highly exothermic reaction due to increase in temperature. There is several side reactions are take place in furnace reactions. These reactions are take place due to destruction of ammonia.

After the flame zone the feed is enter into anoxic reaction at the temperature of $345^{\circ} \mathrm{C}$ and pressure is 1.7 bars. In the Anoxic section there is an endothermic reaction that takes place in this section [14].

$$
\begin{gathered}
\mathrm{CO}_{2}+\mathrm{H}_{2} \mathrm{~S}+\mathrm{H}_{2} \longleftrightarrow \mathrm{S}_{2}+2 \mathrm{H}_{2} \mathrm{O} \\
\mathrm{H}_{2} \mathrm{~S} \longleftrightarrow 1 / 2 \mathrm{~S}_{2}+\mathrm{H}_{2} \\
\mathrm{H}_{2}+\mathrm{CO}_{2} \longleftrightarrow \mathrm{CO}+\mathrm{H}_{2} \mathrm{O} \\
\mathrm{NH}_{3}+3 / 4 \mathrm{SO}_{2} \longrightarrow 1 / 2 \mathrm{~N}_{2}+3 / 2 \mathrm{H}_{2} \mathrm{O}+3 / 8 \mathrm{~S}_{2}
\end{gathered}
$$

This is an adiabatic temperature reaction when ammonia gas and hydrogen gas are reacted with oxygen. The oxidation of ammonia is decreased to zero as increase length of the burner. When the length of burner is increase it causes decrease in production of ammonia gas. $\mathrm{NH}_{3}$ gas is converted into $\mathrm{NH}_{2}$ gas it increases to maximum value but further increase in distance the production of $\mathrm{NH}_{2}$ is decreased due to conversion to nitrogen gas and nitro oxide [15].

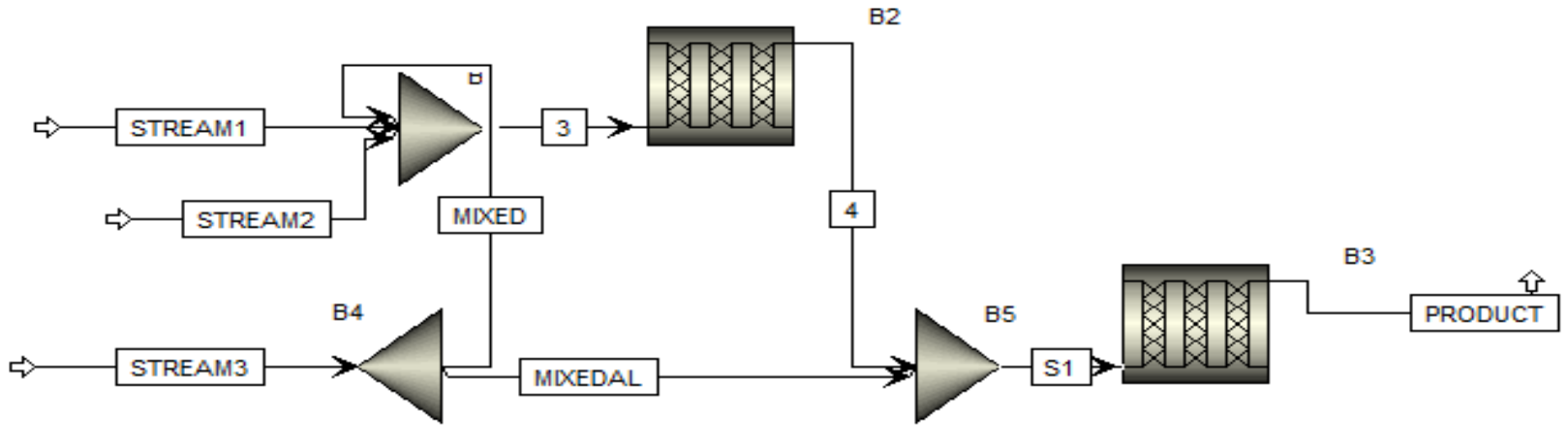

\subsection{Ammonia Production}

Figure 1: Process Flow diagram of Claus Process

\begin{tabular}{lll}
\hline & Heat and Material Balance Table \\
\hline Stream ID & & Product \\
Temperature & F & 2354.9 \\
Pressure & Psia & 30.46 \\
Mole Flow & Lbmol/hr & 1189.931 \\
$\mathbf{H}_{2} S$ & & 273.469 \\
SO2 & & 129.8 \\
Water & & 171.27 \\
CO2 & & 421.139 \\
CO & & 4.624 \\
$\mathbf{H}_{2}$ & & 22.461 \\
\hline
\end{tabular}


Kinetic Reactions Modeling and Optimization of Claus Process

\begin{tabular}{ll}
\hline $\mathbf{N}_{2}$ & 84.538 \\
$\mathbf{N H}_{3}$ & 82.425 \\
$\mathbf{S}_{2}$ & 0.009 \\
$\mathbf{S}_{8}$ & 0 \\
\hline
\end{tabular}

Figure 2: Ammonia Production in Claus Process

\subsection{Modeling and Designing of Claus Process}

There is some kinetic limitation on the equilibrium calculation. They don't provide best information to get maximum recovery of Claus process [16]. It is also notice that Gibbs energy is best tool for modeling and designing of Claus process because of some deficient in kinetic modeling and time consuming calculation. The temperature and product composition is calculated by given equation below:

$\mathrm{G}=\sum_{i=1}^{n c} n i\left(g i+R T \ln \left(\frac{n i P}{n}\right)\right.$

$\sum_{i=1}^{n}$ hi feed ni feed $=\sum_{i=1}^{n}$ hi product ni product

$\mathrm{n}=$ molar flow rate of $\mathrm{i}$-components

$\mathrm{n}=$ total flow rate

$\mathrm{P}=$ total operating Pressure

$\frac{h o}{R T}=a 1+\frac{a 2}{2} T+\frac{a 3}{3} T^{2}+\frac{a 3}{4} T^{3}$

In this equation there are simultaneously solved of mass balance. These are basic algorithm equation is given by Walas equation [17].

\section{Optimization of Claus Process}

An optimization is a process in which making best of anything to get a maximum result. Optimization is an mathematical technique to finding the maximum and minimum value of the different variable and set a constraint and define a linear problem for system analysis. There are two type of optimization parametric optimization and topological optimization [18].

Parametric Optimization 
Kinetic Reactions Modeling and Optimization of Claus Process

In the parametric optimization the process parameter of Claus process is varying continuously. Process parameter is like temperature, pressure and change the concentration of oxygen. Due to change the process variable to get a maximum efficiency of Claus process [19].

\section{Topological Optimization}

A topological optimization is deal with size reduction of equipment. It is deal with maximum consumption of internal utilities and minimum consumption of external utilities. There is some objective of topological optimization [20]. It is deal with:

Recycling and re-entering of feed in the process.

$>$ Reducing and decreasing the number of equipment and size of equipment.

$>$ Improve the process efficiency to get maximum performance.

\section{Optimization Study of Claus Process}

\subsection{Effect of change the diameter of furnace}

When the diameter of reaction furnace is decrease then the production of ammonia gas are reduced. Due to adiabatic reaction the temperature of reaction is increase because $\mathrm{NH}_{3}$ and $\mathrm{H}_{2}$ are reacted with $\mathrm{O}_{2}$ gas [21]. The oxidation of ammonia gas is causes decreased in mole fraction ratio to zero value and on the other hand $\mathrm{NH}_{2}$ is produced at maximum value and further conversion of $\mathrm{NO}$ and $\mathrm{N}_{2}$ when the length of reactor is increased [22].

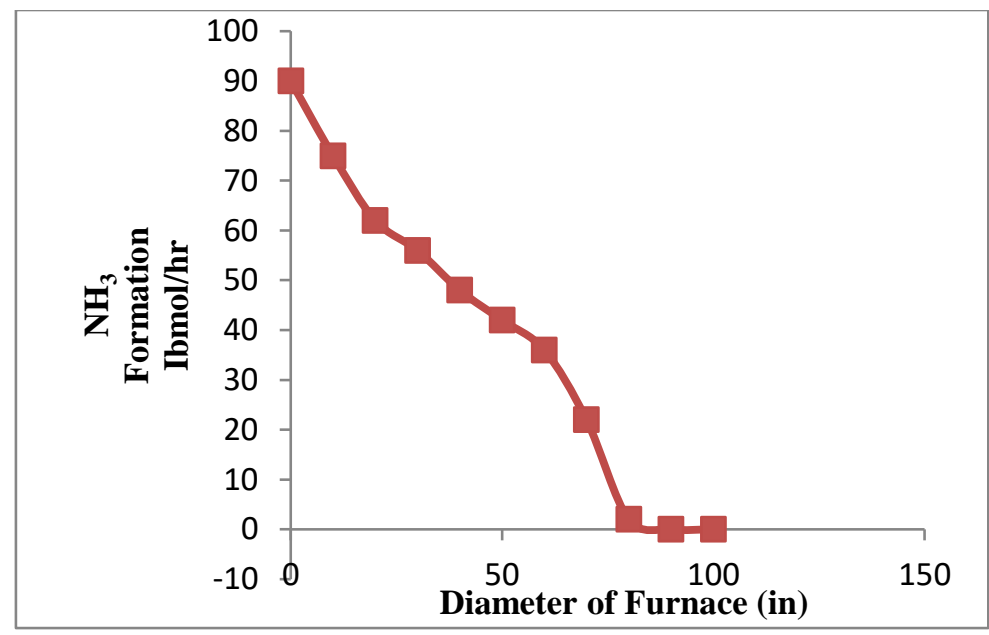

Figure 3: Effect of change the diameter of furnace

\subsection{Effect of increase the oxygen flowrate}


Kinetic Reactions Modeling and Optimization of Claus Process

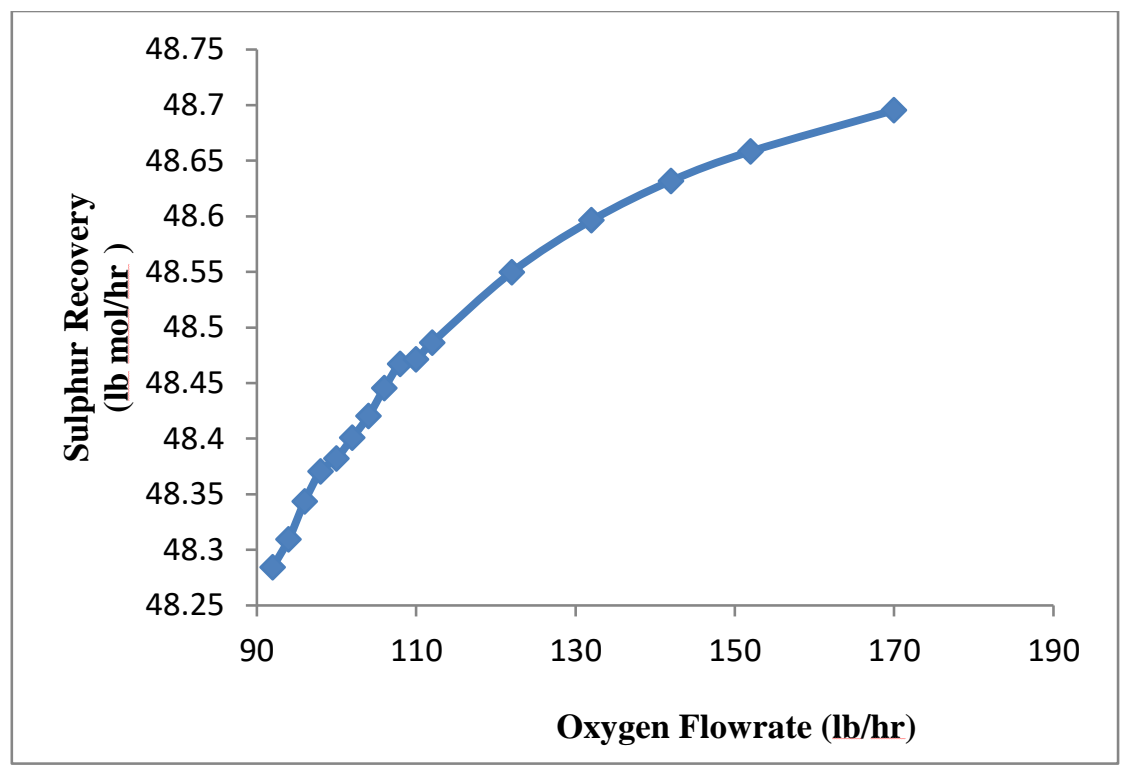

Figure 4: Effect of increase the oxygen flowrate

When the flowrate of oxygen is increasing it causes the conversion of $\mathrm{H}_{2} \mathrm{~S}$ gas into elemental sulfur. The oxygen is limited reactant. It is completely consumed in the first stage of reactor. Due to completely conversion of oxygen reactant the unreacted $\mathrm{H}_{2} \mathrm{~S}$ gas is carried out from existing point. The oxygen is main component for $\mathrm{H}_{2} \mathrm{~S}$ gas conversion into elemental sulfur [23].

\subsection{Effect of Temperature on $\mathrm{H}_{2} \mathrm{~S}$ gas conversion}

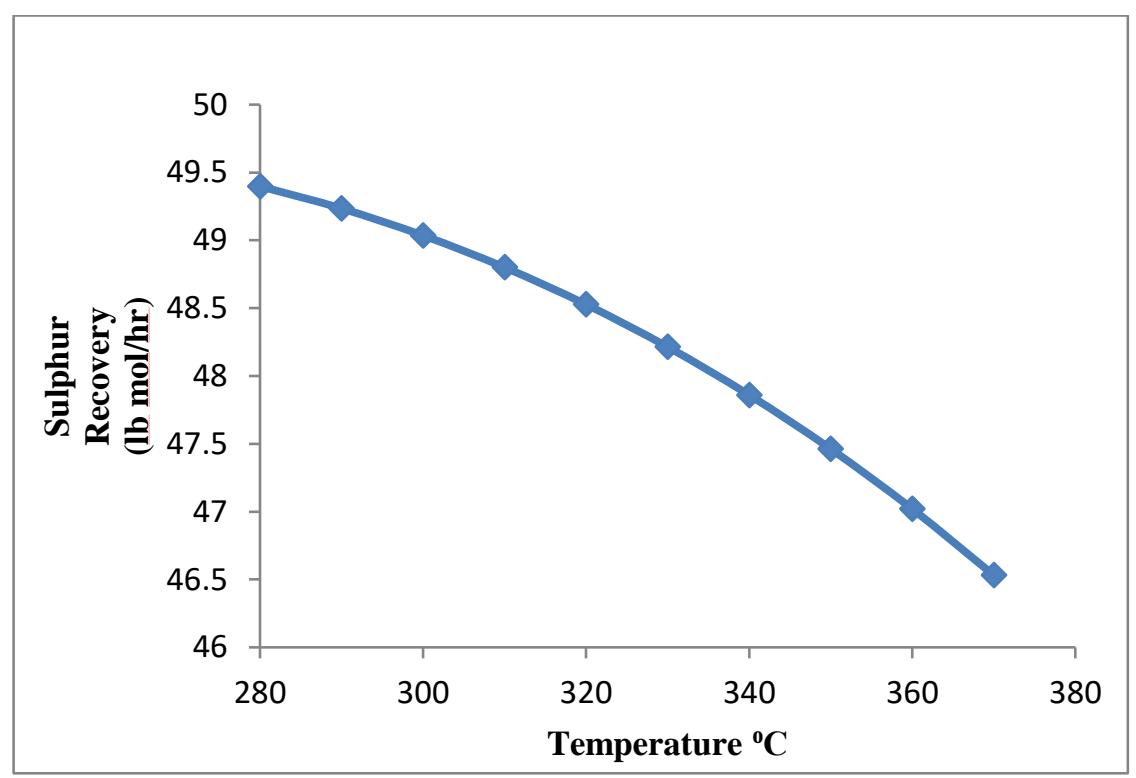

Figure 5: Effect of Temperature on $\mathrm{H}_{2} \mathrm{~S}$ gas conversion

The Claus process is the exothermic reaction in which heat is released during the exothermic reaction. During the heat release toward the systems it causes deactivation of catalyst and more byproduct are formed [24]. During this reactions coke is deposit on the catalyst layer it is causes 
decrease the catalyst performance and it is causes deactivation of catalyst. This diagram is shown that when the temperature of reaction furnace is low the more sulfur is produced. Whenever the temperature is increasing the production of sulfur is increasing and more by product are formed [25]. 
Kinetic Reactions Modeling and Optimization of Claus Process

\subsection{Sensitivity Analysis of Claus Process}

\section{Effect of residence time on the Claus Process}

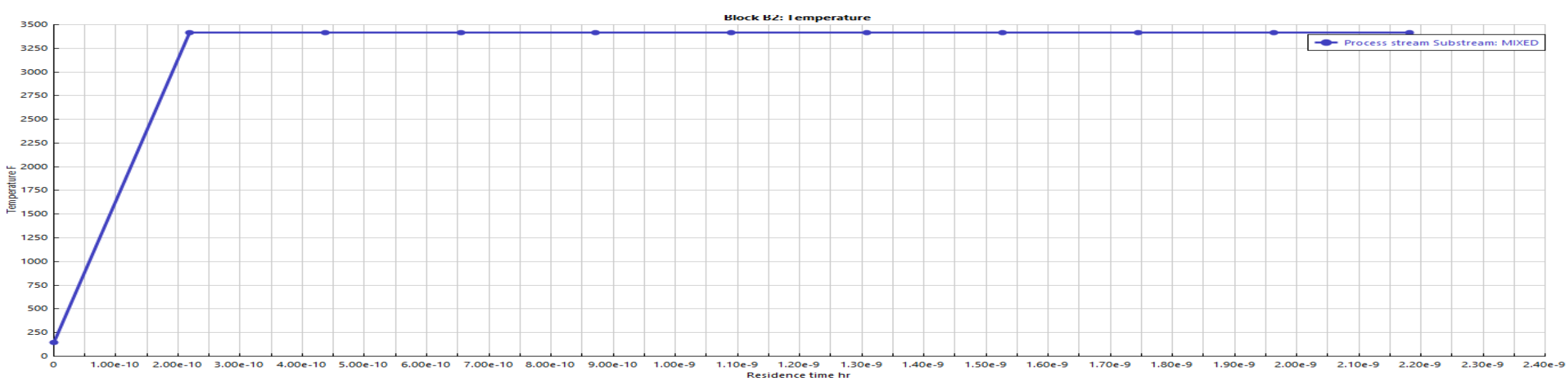

Figure 6: Effect of residence time on Claus Process

\section{Effect of pressure on the Claus Process}

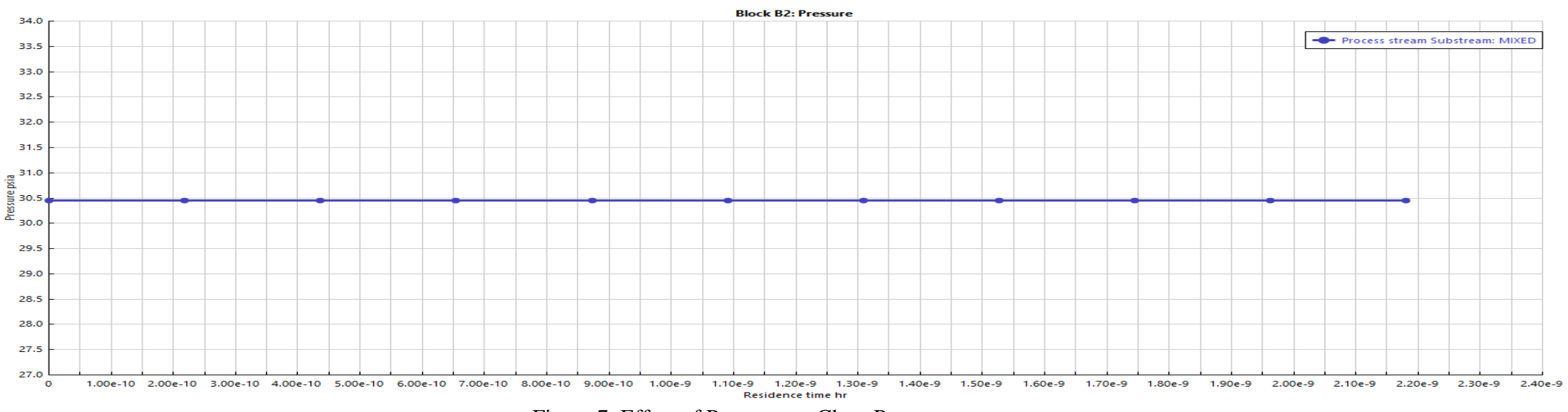

Figure 7: Effect of Pressure on Claus Process 
Kinetic Reactions Modeling and Optimization of Claus Process

\section{Conclusion}

Claus process is a sulfur recovery process in which sulfur is extracted from sour gas. There are different software are used for simulation of Claus process. Aspen Plus is best software for simulation of Claus process. In this research paper we have study the effect of $\mathrm{NH}_{3}$ gas on the Claus process. Due to ammonia gas in the process it is caused corrosion in the chemical equipment. Ammonia gas has causes bad performance on the Claus process. We have studies the effect of diameter on $\mathrm{NH}_{3}$ gas. When the diameter of reaction furnace is increasing then production of ammonia gas is reduced. When the diameter is increased then $\mathrm{NH}_{3}$ gas is converted into $\mathrm{NH}_{2}$ and further $\mathrm{NH}_{2}$ gas is converted into $\mathrm{N}_{2}$ and $\mathrm{SO}_{2}$ gas. We have studies the effect of oxygen flow on the sulfur recovery. When the flowrate of oxygen is increased then unreacted $\mathrm{H}_{2} \mathrm{~S}$ gas is converted into sulfur. Oxygen is limited reactant it is consumed in first stage of the reactor. We have increased the flowrate of oxygen to increase the conversion rate. We have studies the effect of temperature on the Claus process. When the temperature is increased then the recovery of sulfur is decreased. The Claus reaction is exothermic reaction in which a large amount of heat is released. Due to high amount of heat release the catalyst of reactor is caused deactivation, Coking, fouling and agent problem are formed in the catalyst. We have studies the sensitivity analysis of Claus process by changing the pressure, temperature and residence time and study the production of ammonia gas in Claus process. 
Kinetic Reactions Modeling and Optimization of Claus Process

\section{References}

\section{Bibliography}

[1] J. 1. Laperdrix E, "Study of CS2 hydrolysis catalyzed by alumina and titania," Laperdrix E , Justin 1, pp. 167-173, 1998.

[2] K. S. Adedini R, "A simple Molar Flow Modeling and Simulation of Cataytic Bed in Claus Process," Adedini R, Koolivand Salooki, pp. 173-179, 2010.

[3] K. M. Mahdipoor HR, "The effect of Amine Concentration on the performance of TGT Absorber," Mahdipoor HR, Kakavand M, pp. 56-59, 2015.

[4] P. M. Asadi S, "Effect of $\mathrm{H} 2 \mathrm{~S}$ concentration on the reaction furnace temperature," Asadi $S$, Pakizeh $M$, p. 9, 2011.

[5] k.karan, "An experimental and modeling study of Homogeneous Gas Phase Reaction Occuring.," University of Calgray, pp. 711-724, 1998.

[6] H. Bennett, "Hydrogen Sulphide-air equilibria under Claus Furnace Condition," H.A Bennett, pp. 720-724, 1973.

[7] A. B.M Khudenko, "Hydrogen Sulphide- Air equilibria under the Claus Process," B.M Khudenko, A.Mesisen, p. 10, 1993.

[8] F. D. Papasidero, "Design of SRU thermal reactor and WHB considering reactions," F.Maneti D Papasidero, p. 11, 2012.

[9] K. k. L.V Nasato, "Heat transfer and Quenching in modeling a Claus Process Plant," L.V Nasato , K karan, pp. 2651-2655, 1994.

[10] N. P. V.Kaloidas, "Kinetics of thermal non-Catalystic decomposition of H2S," V.Kaloidas, N. Papayannakos, pp. 2493-2500, 1989.

[11] D. H. A.E Cover, "Review of selected sulfur recovery proceess of SNG production," A.E Cover, D.A Hubbard, p. 14, 1985. 
Kinetic Reactions Modeling and Optimization of Claus Process

[12] W. Monnery, "Modelling the Claus process reaction furnace and also impliment of Claus process," W.D Monnery, pp. 711-724, 1993.

[13] N. D. .. J. Hyne, "Kinetics of the reaction between hydrogen and sulfur under the high pressure of Claus," N.I Dowling . J.B Hyne , pp. 2327-2332, 1990.

[14] M. R. B.J Mcbride . S. Gordon, "Coefficients for calculating thermodynamic and transport properties of individual species," B.J Mcbride. S. Gordon, MA Reno, p. 8, 1993.

[15] E. A. MH, "Plant-Wide simulation Model for modified Claus Process Based on simulation data," Eghbal Ahmadi MH, pp. 997-1002, 2017.

[16] M. F. M.Pahalavan, "Modeling and Simulation of Claus unit reaction of furnace," M.Pahalavan, MA Fanei, pp. 50-63, 2015.

[17] f. .. D. Papasidero, "Mutilscaale Modeling of Claus thermal furnance," f.Manenti . D Papasidero, pp. 219-225, 2013.

[18] S. .. E. Ranzi, "Modeling a Claus Process reaction furnace via radical kinetic scheme," S.Pierucci. E. Ranzi, pp. 463-468, 2004.

[19] A. Nabgan W, "Simulation of Claus process and unit reaction furnace," Nabgan W, Amran, p. $8,2016$.

[20] J. S. H. Paskall, "Feild measurments of hydrogen production in an oxygen enriched Claus Process," J.A Sames. H.G Paskall, p. 12, 1992.

[21] L. N. .. K.Karan, "Modeling reaction quech time in waste heat boiler of a Claus process`," L.V Nasato . K.Karan, pp. 1483-1488, 1994.

[22] F. M. A.Bassani, "Novel and Glasification process ; Improvement of syngas and reduction of emmision," A.Bassani , F. Maneneti , pp. 7-13, 1993.

[23] A. G. H.Selim, "Acid gas composition effect on the optimum temperature in Claus process," H.Selim , AK Gupta, p. 14, 2008.

[24] A. M. K.Karan, "A high temperature expermental and modeling study of homogeneous gas phase," K.Karan, A.K Mehrota, pp. 2999-3006, 1999.

[25] F. M. Phalavan M, "Modeling and Simulation of Claus process via Aspen Hysys of Sulfur Recovery," Phalavan M, Faneai MA, pp. 42-52, 2015. 
